\title{
Influence of the molecular weight of carboxymethylcellulose on properties and stability of whey protein-stabilized oil-in-water emulsions
}

\author{
Yan Huan, Sha Zhang, and Bongkosh Vardhanabhuti ${ }^{1}$ \\ Food Science Program, Division of Food systems and Bioengineering, University of Missouri, Columbia 65211
}

\begin{abstract}
The influence of the molecular weight $\left(\mathrm{M}_{\mathrm{w}} ; 270,750\right.$, and $2,500 \mathrm{kDa}$ ) and concentration of carboxymethylcellulose (CMC) on the stability and properties of whey protein isolate (WPI)-stabilized oil-in-water emulsions were assessed by measuring $\zeta$-potential, droplet size, apparent viscosity, protein surface coverage, and creaming stability. Emulsions were prepared to contain $5 \%$ oil, $0.5 \%$ WPI, and 0 to $0.5 \% \mathrm{CMC}$ at $\mathrm{pH} 7$. After emulsification, $\mathrm{pH}$ was adjusted to 5.2. In the absence of CMC, the WPI-stabilized emulsion was unstable to droplet flocculation and coalescence due to the relatively low droplet charge. Emulsions stabilized by mixed WPI-CMC had improved surface properties as well as reduced droplet flocculation, as indicated by increased negative charges and protein surface coverage as well as smaller droplet size. Increased viscosity due to nonadsorbed CMC also contributed to increased stability at high $\mathrm{CMC}$ concentration. The high- $\mathrm{M}_{\mathrm{w}} \mathrm{CMC}$ was more effective in enhancing surface properties and providing better stability against creaming compared with lower- $\mathrm{M}_{\mathrm{w}}$ CMC. Maximum stability was achieved with mixed WPI-CMC stabilized emulsion containing $0.08 \%$ CMC 2,500 kDa.
\end{abstract}

Key words: whey protein isolate, molecular weight, carboxymethylcellulose, emulsion

\section{INTRODUCTION}

Biopolymer interactions are widely used to improve the texture and shelf-life of food products. Many studies on the interactions between protein and polysaccharide have been reported (Pereyra et al., 1997; Laneuville et al., 2000; Turgeon et al., 2003; Neirynck et al., 2007; Dickinson, 2008; Schmitt and Turgeon, 2011). Functional properties of protein are generally improved by complexation with other polysaccharides. The formation and solubility of protein-polysaccharide complexes

Received August 18, 2015.

Accepted December 10, 2015.

${ }^{1}$ Corresponding author: vardhanabhutib@missouri.edu mainly depend on $\mathrm{pH}$, ionic strength, biopolymer ratio, and concentration. Other factors, such as types of biopolymers (charge density, molecular weight, and so on), temperature, and pressure, also influence the complex formation (Schmitt and Turgeon, 2011). The formation of protein-polysaccharide complex reaches the maximum at $\mathrm{pH}$ values below or around the isoelectric point ( $\mathbf{p I}$ ) of protein due to the opposite charge carried by these 2 biopolymers. However, at $\mathrm{pH}$ values above the $\mathrm{pI}$ of proteins (e.g., at neutral $\mathrm{pH}$ ), electrostatic interactions between protein and anionic polysaccharide can still occur (Doublier et al., 2000; Girard et al., 2002a; Vardhanabhuti et al., 2009). In this case, electrostatic interactions between anionic groups of the polysaccharide and positively charged local patches on the proteins are involved (Dickinson, 1998).

Two alternative procedures can be used for stabilization of oil droplets by protein-polysaccharide electrostatic complex: bilayer emulsion preparation and mixed emulsion preparation (Jourdain et al., 2008). The socalled layer-by-layer technique is used for the preparation of bilayer emulsions whereby polysaccharide is added to a protein-stabilized emulsion system. Mixed emulsions are prepared by emulsifying the oil and water in the presence of soluble protein-polysaccharide complexes, which adsorb onto the oil droplet surface directly (Jourdain et al., 2009). When prepared at $\mathrm{pH}$ 6 , the mixed caseinate-dextran sulfate solution formed a soluble complex, rather than a coacervate, and the emulsion obtained by this approach gave much stronger dilatational viscoelastic properties of the interfacial film than the bilayer emulsion, leading to a more stable behavior of emulsion system (Jourdain et al., 2009). In double emulsion, Lutz et al. (2009) reported that once a soluble whey protein isolate-pectin complex was formed at $\mathrm{pH} 6$, and the resulting emulsion was stable with small droplet size, minimum creaming, and low water transport across the oil layer.

Polysaccharide plays an important role in a proteinstabilized emulsion and has a great influence on the emulsion properties (Dickinson, 2003). Various research have been reported on the addition of polysaccharide to enhance the properties and stability of protein-stabi- 
lized oil-in-water emulsions (Dickinson and Pawlowsky, 1997; Ye et al., 2000; Surh et al., 2006; Neirynck et al., 2007; Long et al., 2013). Although the stabilization of emulsion is primarily dependent on the concentration of polysaccharide, molecular properties of polysaccharides can significantly influence emulsification properties. It has been reported that whey protein-stabilized emulsions with low molecular weight $\left(\mathbf{M}_{\mathbf{w}}\right)$ and a low degree of deacetylation of chitosan were less stable compared with those stabilized by higher $\mathrm{M}_{\mathrm{w}}$ and degree of deacetylation due to the loss of interfacial coadsorption efficiency and interfacial net charge (Laplante et al., 2005b). Du et al. (2009) reported that CMC with high $\mathrm{M}_{\mathrm{w}}$ and a high degree of substitution increased the viscosity of the solutions and the electrostatic repulsion between casein particles, respectively, leading to the long-term stability of acidified skim milk drinks.

Whey protein isolate (WPI) is one of the most used proteins in food emulsions due to its excellent surface activity (Goff, 2014). The emulsification properties of WPI mixed with different polysaccharides have been widely studied (Girard et al., 2002c; Singh et al., 2003; Laplante et al., 2005a; Sun et al., 2007; Klein et al., 2010; Li et al., 2012a). Carboxymethylcellulose (CMC) is an anionic water-soluble polysaccharide and has been used in a wide range of food products (Nussinovitch, 1997). It has been demonstrated that WPI/CMC complex formed at $\mathrm{pH} 4.2$ was more effective in protecting oil droplets against coalescence than emulsion containing WPI alone due to higher protein load (Girard et al., 2002b). The use of WPI-CMC complexes as emulsifiers led to larger amounts of adsorbed protein that would be involved in the network formation between complexes. Increased protein packing at the surface could be due to the reduced electrostatic repulsion between the positive protein molecules by the negatively charged polysaccharide (Ganzevles et al., 2006). Koupantsis and Kiosseoglou (2009) reported that by complexation of whey protein with $\mathrm{CMC}$ at $\mathrm{pH}$ value below $\mathrm{pI}$, interactions are more enhanced at lower $\mathrm{pH}$, leading to an increased stabilization of whey protein-stabilized emulsion during aging, heating, or freezing. To the best of our knowledge, emulsification properties of WPI-CMC complex formed at neutral $\mathrm{pH}$ and the effect of the molecular weight of CMC on WPI-stabilized emulsion have not been studied.

The objective of our study was to investigate the emulsification properties of emulsions formed by first preparing a bulk aqueous solution of WPI-CMC complex at $\mathrm{pH} 7.0$ before emulsification and $\mathrm{pH}$ adjustment to 5.2. The emulsification and stabilization properties of WPI are limited at or near $\mathrm{pI}(\mathrm{pH} \sim 5.2)$; thus, improved properties of the protein at or near $\mathrm{pI}$ will be beneficial for the industry. The influence of the $\mathrm{M}_{\mathrm{w}}$ and concentration of CMC on the interactions between CMC and WPI and emulsification properties and stability of emulsion system was investigated. Our study can provide a better understanding of how molecular size of polysaccharide affect the biopolymer interactions at the interface in mixed emulsion systems. The outcomes could be used to select proper conditions in designing food emulsions having $\mathrm{pH}$ values near $\mathrm{pI}$ of the protein.

\section{MATERIALS AND METHODS}

\section{Materials}

Whey protein isolate Bipro was provided by Davisco Foods International Inc. (Le Sueur, MN). According to the manufacturer, WPI contained $97.9 \%$ protein and $1.8 \%$ ash on a dry basis. The CMC with the average $\mathrm{M}_{\mathrm{w}}$ of $270 \mathrm{kDa}$ (CMC 270k), $750 \mathrm{kDa}$ (CMC 750k), and $2,500 \mathrm{kDa}$ (CMC 2,500k) were provided by $\mathrm{CP}$ Kelco Inc. (Atlanta, GA). Phosphate buffer solutions ( $5 \mathrm{mM}, \mathrm{pH} 7$ and 5.2) were made with Milli-Q water ( $>18.2 \mathrm{M} \Omega / \mathrm{cm}$; Millipore, Billerica, MA). Commercial vegetable oil was purchased from local supermarket and all the other reagents were of analytical grade.

\section{Preparation of Stock Solutions}

The WPI stock solution (10\%, wt/wt) was prepared by slowly dissolving protein powder into $5 \mathrm{~m} M$ phosphate buffer at $\mathrm{pH} 7$ and kept stirred at room temperature for at least $2 \mathrm{~h}$. Carboxymethylcellulose stock solution (1\%, wt/wt) was prepared by slow addition of CMC powder into phosphate buffer at $\mathrm{pH} 7$ and at $80^{\circ} \mathrm{C}$ for $1 \mathrm{~h}$ under continuous stirring. After heating, the CMC stock solution was cooled to ambient temperature before weight adjustment to bring the concentration back to $1 \%$. The 2 stock solutions were stored at $4^{\circ} \mathrm{C}$ overnight for complete hydration.

\section{Preparation of Emulsions}

All oil-in-water emulsions containing 5\% (wt/wt) oil, $0.5 \%$ (wt/wt) protein, and 0 to $0.5 \%$ (wt/wt) CMC were obtained by emulsification of oil with aqueous WPI-CMC complex solutions through a 2-stage process. The WPI-CMC complexes were prepared by mixing the biopolymers and water at an appropriate amount and the $\mathrm{pH}$ was adjusted to 7.0. The WPI-CMC mixtures were stirred for at least $1 \mathrm{~h}$ before addition of oil and emulsification. Coarse emulsions were prepared by blending $5 \%$ oil and $95 \%$ aqueous solution together 
using a laboratory homogenizer, Ultra Turrax T-25 (IKA Instruments, Staufen, Germany) at 12,000 rpm for 1 min at room temperature. Final emulsion samples were obtained by using an ultrasonic processor (Sonics VC 505, power $500 \mathrm{~W}$, frequency $24 \mathrm{kHz}$; Sonics, Newtown, CT) with a sonotrode $(3 \mathrm{~mm}$, approximate length $=100 \mathrm{~mm}$, titanium) for $5 \mathrm{~min}$ (30\% amplitude of maximum power). Sodium azide $(0.02 \%)$ was added as an antimicrobiological agent. After emulsification, the emulsions were slowly acidified to $\mathrm{pH} 5.2$ by adding $0.1 \mathrm{M} \mathrm{HCl}(50 \mu \mathrm{L}$ at a time). The acidified emulsions were stirred for at least $1 \mathrm{~h}$ before analysis to allow the $\mathrm{pH}$ to stabilize.

\section{Zeta-Potential Measurement}

Measurement of $\zeta$-potential was carried out using the Zetasizer Nano ZS (Malvern Instruments Ltd., Worcestershire, UK) equipped with a $633-\mathrm{nm}$ laser and $173^{\circ}$ detection optics at $25^{\circ} \mathrm{C}$. Each sample was diluted at a ratio of 1:250 using $5 \mathrm{mM}$ phosphate buffer at $\mathrm{pH}$ 5.2 to prevent multiple scattering effects. An individual $\zeta$-potential measurement was determined from the average of 5 readings taken on the same sample. All the measurements were carried out in duplicate.

\section{Droplet Size Determination}

Droplet size distributions were determined with a Coulter Multisizer (Coulter Electronics Ltd., Luton, England) at room temperature. Each sample was diluted with $5 \mathrm{~m} M$ phosphate buffer at $\mathrm{pH} 5.2$ at a ratio of 1:1,000. The volume mean diameter of the sample was used as the average droplet size. All measurements were repeated at least twice.

\section{Creaming Stability of the Emulsion}

Fresh emulsion sample $(10 \mathrm{~mL})$ was pipetted into a cylindrical glass tube (internal diameter $=16 \mathrm{~mm}$, height $=100 \mathrm{~mm}$ ). Subsequently, the tubes were sealed with Parafilm M film (Pechiney Plastic Packaging Company, Chicago, IL) to prevent evaporation. Emulsion samples were stored quiescently at ambient temperature $\left(\sim 25^{\circ} \mathrm{C}\right)$ for $15 \mathrm{~d}$. Emulsion stability evolution was determined by measurement of height (millimeter units) of a distinctive clear or semitransparent bottom serum phase layer on d 5, 10, and 15 after emulsion preparation. The extent of creaming was characterized by creaming index $(\mathrm{CI}, \%)=\left(\mathrm{H}_{\mathrm{S}} / \mathrm{H}_{\mathrm{T}}\right) \times 100 \%$, where $\mathrm{H}_{\mathrm{S}}$ is the height of the serum layer and $\mathrm{H}_{\mathrm{T}}$ is the initial height of the emulsion. Each creaming index of an emulsion sample was recorded in duplicate.

\section{Rheological Properties Measurement}

Rheological properties of fresh emulsions were measured using a Kinexus Rheometer (Malvern Instruments Ltd.) equipped with a cone (40-mm diameter, $4^{\circ}$ angle) and plate geometry. Emulsion sample was loaded on a lower plate and the upper cone geometry was gently lowered to a gap of $0.05 \mathrm{~mm}$. Flow behavior of the sample was conducted under a shear rate ramp from $0.1 / \mathrm{s}$ to $200 / \mathrm{s}$ at $25^{\circ} \mathrm{C}$ and under a solvent trap setting to prevent evaporation. Flow behavior index and consistency coefficient were calculated using the power law model. Each treatment was measured in duplicate.

\section{Determination of Protein Surface Coverage}

The concentration of protein adsorbed at the oil-water interface was determined according to the method described by (Ye et al., 2000) with slight modification. The fresh emulsions were centrifuged at a speed of $13,000 \times g$ for $60 \mathrm{~min}$ at $20^{\circ} \mathrm{C}$ in a temperaturecontrolled centrifuge (Beckman Coulter, Inc., Fullerton, CA). The subnatants were carefully removed using a pipette and filtered. The total protein content of subnatants was analyzed by Kjeldahl method $(\mathrm{N} \times$ $6.38)$. The protein surface coverage $\left(\mathrm{mg} / \mathrm{m}^{2}\right)$ was then calculated from the mean diameter of the oil droplets determined by the Multisizer (Coulter Electronics Ltd.) and the difference between the amount of protein used to prepare the emulsion and those measured in the subnatant after centrifugation. All the measurements were done in duplicate.

\section{Statistical Analysis}

We used SPSS software (version 21, SPSS Inc., Chicago, IL) to analyze significant differences $(P<0.05)$ between the properties of gels by one-way ANOVA. The comparisons between the mean values were evaluated by Tukey's honestly significant difference (HSD) test.

\section{RESULTS AND DISCUSSION}

\section{Formation of WPI-CMC Complex on Oil Droplets}

The influences of $\mathrm{M}_{\mathrm{w}}$ of $\mathrm{CMC}$ on the $\zeta$-potential of emulsion droplets as a function of CMC concentration were shown in Figure 1. In the absence of CMC, the net charge of the emulsion droplets was slightly negative $(-2.22 \mathrm{mV})$, which demonstrated that $\mathrm{pH} 5.2$ was the $\mathrm{pH}$ value very close to the $\mathrm{pI}$ of whey protein and that the net droplet charge was close to zero. The addition of CMC caused an appreciable change in the CMC con- 
centration dependence of the net droplet charge. When CMC was added to WPI solution before emulsification, the $\zeta$-potential of the droplets drastically became more negative, even at $0.04 \% \mathrm{CMC}(-26.7$ to $-30.2 \mathrm{mV})$. This is because negatively charged groups of CMC electrostatically bind to positively charged patches of WPI on the droplet surface, increasing the electrostatic repulsions between droplets and showing negative $\zeta$-potential values. Increasing CMC concentration led to more negative $\zeta$-potential, which implied that more CMC molecules absorbed onto the surface of the oil droplets. When the CMC concentration exceeded $0.3 \%$, the $\zeta$-potential appeared to be constant, suggesting that the droplet surfaces were almost saturated by WPI-CMC complexes or that increased electrostatic repulsion prevented further CMC adsorption. Similar types of electrostatic interactions between anionic polysaccharides and proteins in emulsions have been reported previously (Guzey and McClements, 2007; Harnsilawat et al., 2006; Jourdain et al., 2008; Li et al., 2012a). The surface charge on $\beta$-LG-stabilized emulsion droplets became more negative as carrageenan or pectin concentration increased and reached a plateau value as the surfaces of the droplets were saturated with polysaccharide (Guzey and McClements, 2007). In Liu et al. (2012), at pH 5 to 7 , the $\zeta$-potential of casein-coated droplets increased with increasing CMC concentration and became constant as the CMC concentration exceeded $0.3 \%$.

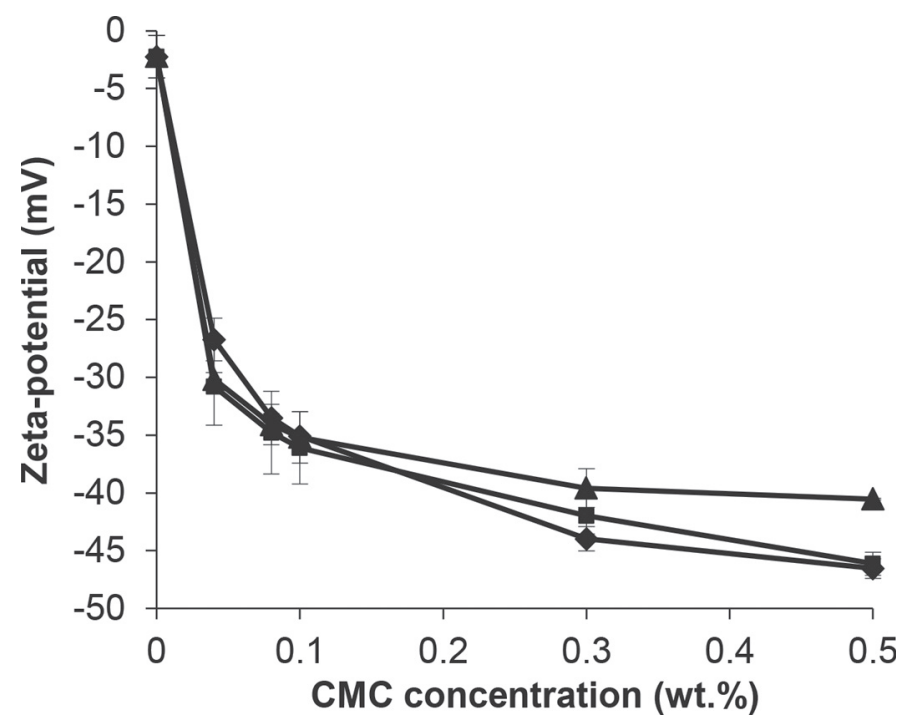

Figure 1. Dependence of electrical charge of emulsion droplets (zeta-potential) on carboxymethylcellulose (CMC) concentration and molecular weight; (ム) CMC $270 \mathrm{kDa},(\boldsymbol{\square}) \mathrm{CMC} 750 \mathrm{kDa},(\diamond) \mathrm{CMC}$ $2,500 \mathrm{kDa}$. Error bars represent SD.
The molecular characteristics of a charged molecule could influence its ability to adsorb to the surface of an oppositely charged droplets. We also investigated the effect of $\mathrm{M}_{\mathrm{w}}$ of $\mathrm{CMC}$ on the adsorption of $\mathrm{CMC}$ to oil droplet surfaces. Interestingly, no clear difference was noted in the $\zeta$-potential of emulsion droplets with regard to the effect of $\mathrm{M}_{\mathrm{w}}$ of $\mathrm{CMC}$ in emulsions containing up to $0.1 \% \mathrm{CMC}$. At $0.3 \%$, the $\zeta$-potential of emulsions containing CMC 2,500k was significantly more negative than that containing CMC 270k, and at $0.5 \%$ emulsions containing $750 \mathrm{k}$ and $2,500 \mathrm{k}$ were significantly more negative than that containing CMC $270 \mathrm{k}$. These results suggest that, at lower concentrations, the electrostatic attraction between the cationic droplet surfaces and the anionic CMC molecules that favor adsorption was probably fairly similar for all CMC. However, the entropy of mixing effect that opposes adsorption would have been much greater for the lower $\mathrm{M}_{\mathrm{w}}$ than the higher $\mathrm{M}_{\mathrm{w}}$ ones because of its much higher number concentration (McClements, 2005). A similar result on the effect of the $\mathrm{M}_{\mathrm{w}}$ of CMC on the formation of complexes between casein micelles and CMC was reported by Du et al. (2009), who reported the addition of a high- $\mathrm{M}_{\mathrm{w}} \mathrm{CMC}$ resulted in a larger increase in the $\zeta$-potential of CMC-coated casein micelles at $\mathrm{pH}$ above 3.7 compared with low- $\mathrm{M}_{\mathrm{w}} \mathrm{CMC}$.

\section{Mean Particle Diameter of the Oil Droplets}

The effect of CMC concentration and $\mathrm{M}_{\mathrm{w}}$ on the average size of the oil droplets is shown in Figure 2. When the $\mathrm{pH}$ of WPI-stabilized emulsion without CMC was acidified from 7.0 to 5.2 , the mean particle diameter of the droplets significantly increased from 1.7 to $9.3 \mu \mathrm{m}$ (data not shown), indicating a high degree of droplet aggregation. This could be attributed to the fact that the $\mathrm{pH}$ was close to the $\mathrm{pI}$ of the adsorbed WPI molecules, hence the electrostatic repulsion between the droplets was too small to prevent aggregation (Surh et al., 2006; Guzey and McClements, 2007; Li et al., 2012a). The addition of CMC even at $0.04 \%$ significantly reduced the droplet size (compared with control), indicating the reduction in droplet aggregation due to the overall increased negative charges on the surface of the droplets. However, the observed large standard deviations were a clear indication that the system was unstable due to large aggregation or flocculation of the oil droplets (Khalloufi et al., 2009). It is possible that the net charge on the droplets was at the border where stable colloid might be achieved, thus the electrostatic repulsion might be insufficient to completely prevent aggregation. In addition, CMC molecules might adsorb to the surface of more than one emulsion droplet dur- 
ing the emulsification, leading to bridging flocculation (Pinotti et al., 1997). With increasing CMC concentration up to $0.1 \%$, the average droplet sizes continued to decrease, which coincided with higher negative charge of the droplets. At $0.1 \% \mathrm{CMC}$, the average droplet sizes for CMC 270k, $750 \mathrm{k}$, and 2,500k were $4.7,4.3$, and 3.7 $\mu \mathrm{m}$, respectively. At high $\mathrm{CMC}$ concentrations of 0.3 and $0.5 \%$, the droplet size appeared to be constant and aggregation became much more limited. Under these conditions, it is likely that enough CMC molecules are available to form complexes with the protein and the droplets are effectively stabilized by both electrostatic and steric interactions. This result was in agreement with other studies showing that anionic polysaccharides can reduce the aggregation of protein-stabilized emulsion droplets at $\mathrm{pH}$ near $\mathrm{pI}$ of the proteins (Surh et al., 2006; Liu et al., 2012). The size of the droplets decreased with increasing anionic polysaccharide concentration before staying constant after a certain polysaccharide concentration (Jourdain et al., 2008).

It is interesting to point out that significant differences in the effect of $\mathrm{M}_{\mathrm{w}}$ of $\mathrm{CMC}$ on droplet size were observed only at $0.08 \%$ CMC. The emulsion prepared with CMC 2,500k had smaller droplet size $(3.6 \mu \mathrm{m})$ than that prepared with CMC 270k $(5.5 \mu \mathrm{m})$ or CMC $750 \mathrm{k}(5.5 \mu \mathrm{m})$. The result observed here was different from previous research, which showed larger average droplet size in emulsion prepared with higher molecular mass soy-soluble polysaccharide due to the formation of thicker layer on the oil droplets (Nakamura et al., 2006). A similar phenomenon was observed by Du et al. (2009), who pointed out that high- $\mathrm{M}_{\mathrm{w}} \mathrm{CMC}$ formed thick adsorbed layer onto caseinate micelles, leading to a larger size of caseinate micelles than low- $\mathrm{M}_{\mathrm{w}} \mathrm{CMC}$. On the other hand, the thicker adsorbed layer could provide better steric stabilization, prevent flocculation, and lead to the formation of smaller droplet size (Chern 2008). At CMC concentrations of 0.3 and $0.5 \%$, we observed no change in droplet size and no difference among CMC with different $\mathrm{M}_{\mathrm{w}}$. This could be due to the saturated coverage of CMC molecules on the surfaces of oil droplets and the excess CMC molecules would be present in the aqueous phase of the emulsions.

\section{Rheological Behavior of Emulsions}

Rheological properties of fresh emulsions were measured immediately after the preparation of the emulsions. Plots of apparent viscosity versus shear rate for WPI/CMC-stabilized emulsions containing different concentrations and $\mathrm{M}_{\mathrm{w}}$ of $\mathrm{CMC}$ are shown in Figure 3. Power law model was applied to further describe the rheological properties. The values of consistency

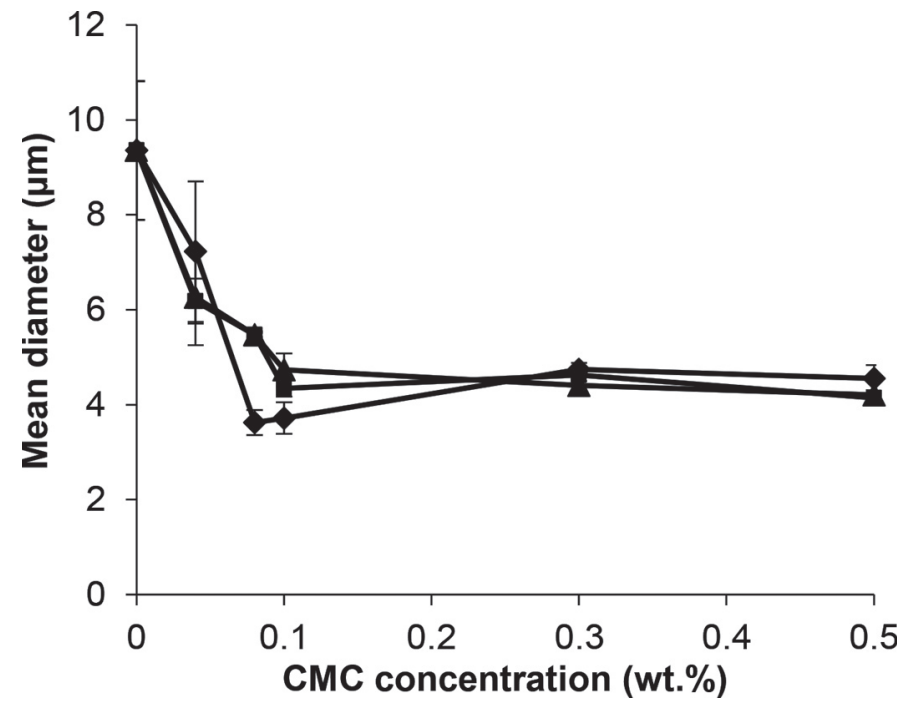

Figure 2. Dependence of mean volume diameter of emulsion droplets on carboxymethylcellulose (CMC) concentration and molecular weight; (ム) CMC $270 \mathrm{kDa}$, (ロ) CMC $750 \mathrm{kDa}$, ( ) CMC 2,500 kDa. Error bars represent SD.

coefficient $(\mathbf{m})$ and flow behavior index $(\mathbf{n})$ are listed in Table 1. Consistency coefficient is a measure of viscosity and its trend is in agreement with that of viscosity versus shear rate presented in Figure 3. The flow behavior index indicates the shear-thinning (n $<1)$, dilatant $(\mathrm{n}>1)$, or Newtonian $(\mathrm{n}=1)$ behavior. Nonflocculated emulsions containing small droplets with less effective volume typically show Newtonian behavior. Flocculated emulsions are known to exhibit pronounced shear-thinning behavior due to the results of progressive deformation and disruption of flocs as shear rate increased (Quemada and Berli, 2002).

In the absence of CMC, the emulsion exhibited a shear-thinning behavior with $\mathrm{n}$ value of 0.664 and $\mathrm{m}$ value of 0.017 at relatively low shear rates, as the apparent viscosity decreased with increasing shear rate, but with a deflection point. This deflection point might be due to the disruption of flocs at this shear rate, thus decreasing the effective volume fraction and lowering the viscosity with further increasing shear rate (Franco et al., 1995, Lorenzo et al., 2008). Similar behavior was shown in caseinate-stabilized emulsion at $\mathrm{pH} 5$ (Surh et al., 2006) and 6 (Jourdain et al., 2009). In the presence of CMC, the emulsions showed a change in flow behaviors depending on the $\mathrm{M}_{\mathrm{w}}$ and concentration of CMC. Emulsions containing 0.04\% CMC 2,500k and $0.08 \%$ CMC 270k and 750k exhibited more Newtonian behavior, with much lower viscosity at relatively low shear rates compared with those without CMC. As shown previously, the average droplet sizes of these 
Table 1. Power law model parameters for emulsions with different carboxymethylcellulose (CMC) concentrations and molecular weight $\left(\mathrm{M}_{\mathrm{w}}\right)$

\begin{tabular}{llcc}
\hline $\mathrm{M}_{\mathrm{w}}$ & $\mathrm{CMC}(\%)$ & $\mathrm{m}^{\mathrm{1}}\left(\mathrm{Pa} \cdot \mathrm{s}^{\mathrm{n}}\right)$ & $\mathrm{n}^{1}$ \\
\hline CMC $270 \mathrm{kDa}$ & 0.04 & $0.012^{\mathrm{ab}}$ & $0.748^{\mathrm{a}}$ \\
& 0.08 & $0.005^{\mathrm{a}}$ & $0.961^{\mathrm{b}}$ \\
& 0.1 & $0.005^{\mathrm{a}}$ & $0.940^{\mathrm{b}}$ \\
& 0.3 & $0.010^{\mathrm{ab}}$ & $0.860^{\mathrm{ab}}$ \\
$\mathrm{CMC} 750 \mathrm{kDa}$ & 0.5 & $0.017^{\mathrm{bc}}$ & $0.822^{\mathrm{ab}}$ \\
& 0.04 & $0.010^{\mathrm{ab}}$ & $0.765^{\mathrm{a}}$ \\
& 0.08 & $0.004^{\mathrm{a}}$ & $0.981^{\mathrm{b}}$ \\
$\mathrm{CMC} 2,500 \mathrm{kDa}$ & 0.1 & $0.004^{\mathrm{a}}$ & $0.993^{\mathrm{b}}$ \\
& 0.3 & $0.007^{\mathrm{ab}}$ & $0.983^{\mathrm{b}}$ \\
& 0.5 & $0.024^{\mathrm{c}}$ & $0.934^{\mathrm{b}}$ \\
& 0.04 & $0.006^{\mathrm{a}}$ & $0.925^{\mathrm{b}}$ \\
& 0.1 & $0.004^{\mathrm{a}}$ & $0.992^{\mathrm{b}}$ \\
& 0.3 & $0.003^{\mathrm{a}}$ & $0.872^{\mathrm{ab}}$ \\
& 0.5 & $0.018^{\mathrm{bc}}$ & $0.886^{\mathrm{ab}}$ \\
\hline
\end{tabular}

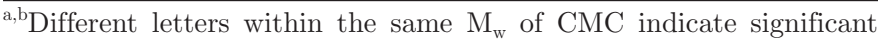
differences $(P<0.05)$.

${ }^{1}$ Consistency coefficient $(\mathrm{m})$ and flow behavior index (n) were determined by fitting flow curves to the Power Law model. The data were the average from 3 measurements.

emulsions were significantly lower than that of WPIstabilized emulsion. This result suggested a high degree of droplet flocculation in emulsion prepared with WPI alone and the addition of CMC could prevent the formation of large droplets or flocculation due to increased negative charge. As the change in flow behavior (e.g., more Newtonian with lower viscosity) was observed at lower CMC concentration for CMC 2,500k compared with CMC 270k and $750 \mathrm{k}$, this is in agreement with previous result which showed that high- $\mathrm{M}_{\mathrm{w}} \mathrm{CMC}$ was more effective in stabilizing the emulsions. At higher CMC concentrations (e.g., 0.3 and $0.5 \%$ ), flow behaviors became more shear-thinning with increasing consistency index (e.g., higher viscosity). As no change in the droplet sizes was observed, increased shear-thinning behavior and consistency index could be due to the nonadsorbed CMC in the aqueous phase.

Though all samples showed the change in rheological behavior from shear-thinning to Newtonian (with lower viscosity) and back to shear-thinning (with higher viscosity), the concentrations where these changes occurred were different among different $\mathrm{M}_{\mathrm{w}}$. The flow behavior of emulsions prepared with CMC 2,500k shifted from shear-thinning (control) to Newtonian at 0.04\%, and back to shear-thinning at $0.1 \%$; however, the concentrations where these changes occurred for emulsions prepared with $\mathrm{CMC} 750 \mathrm{k}$ and $270 \mathrm{k}$ were at $0.08 \%$. At $0.04 \%$ CMC, emulsion with CMC 2,500k showed a change in rheological behavior from shear-thinning of highly flocculated emulsion of WPI (no CMC) to Newtonian behavior with significant decreased viscosity, whereas those with CMC 270k and 750k still showed
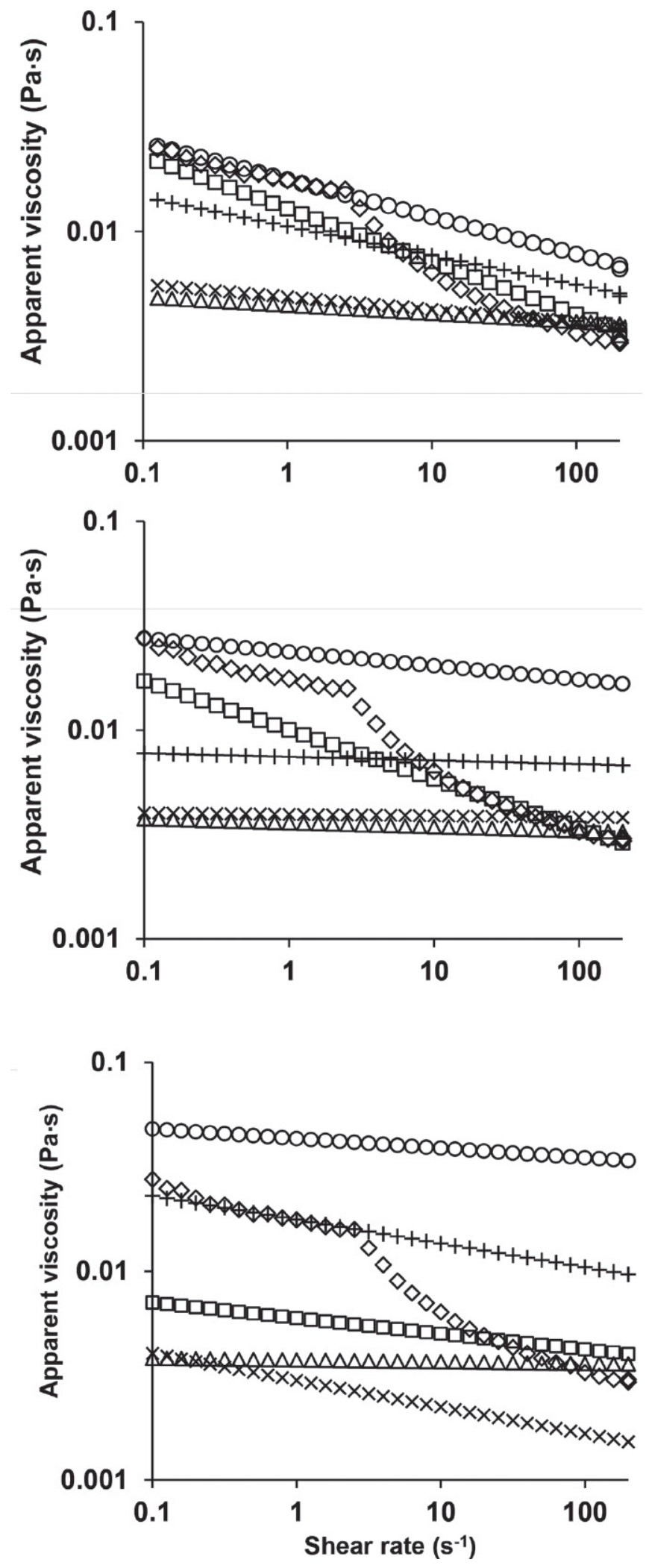

Figure 3. Apparent viscosity of fresh emulsions prepared with different carboxymethylcellulose (CMC) concentrations ( $\diamond=$ control; $\square$ $=0.04 \% ; \Delta=0.08 \% ; \times=0.1 \% ;+=0.3 \% ; \bigcirc=0.5 \%)$ and molecular weight. (a) CMC $270 \mathrm{kDa}$; (b) CMC $750 \mathrm{kDa}$; (c) CMC 2,500 kDa. 
shear-thinning behavior. This suggested that emulsions stabilized by WPI-CMC $2,500 \mathrm{k}$ were nonflocculated at $0.04 \%$, whereas those with CMC 270k and $750 \mathrm{k}$ remained flocculated. The effect of $\mathrm{M}_{\mathrm{w}}$ was also shown at $0.5 \%$ CMC concentration, where higher consistency index was observed with higher- $\mathrm{M}_{\mathrm{w}} \mathrm{CMC}$.

\section{Protein Surface Coverage}

The adsorbed protein on the surface of the oil droplets forms the viscoelastic interfacial film and determines the stability of emulsion system due to its important role in competition or cooperation with other biopolymers (Long et al., 2013). Figure 4 shows the significant effect of $\mathrm{CMC}$ concentration and $\mathrm{M}_{\mathrm{w}}$ on the protein surface coverage of acidified WPI/CMC-stabilized oil droplets. The lowest protein surface coverage $\left(0.22 \mathrm{mg} / \mathrm{m}^{2}\right)$ was observed for the emulsion without CMC addition. The protein surface coverage significantly increased $(P<$ 0.05 ) to $0.49,0.82$, and $0.84 \mathrm{mg} / \mathrm{m}^{2}$ with $0.04 \% \mathrm{CMC}$ $270 \mathrm{k}, 750 \mathrm{k}$, and $2,500 \mathrm{k}$, respectively. Higher protein surface coverage indicated that the formation of WPICMC complex resulted in a collective and cooperative adsorption of whey protein and CMC onto oil-water interface (Li et al., 2012b). Improved surface activity of whey protein contributed to reduced flocculation during emulsion formation compared with emulsion

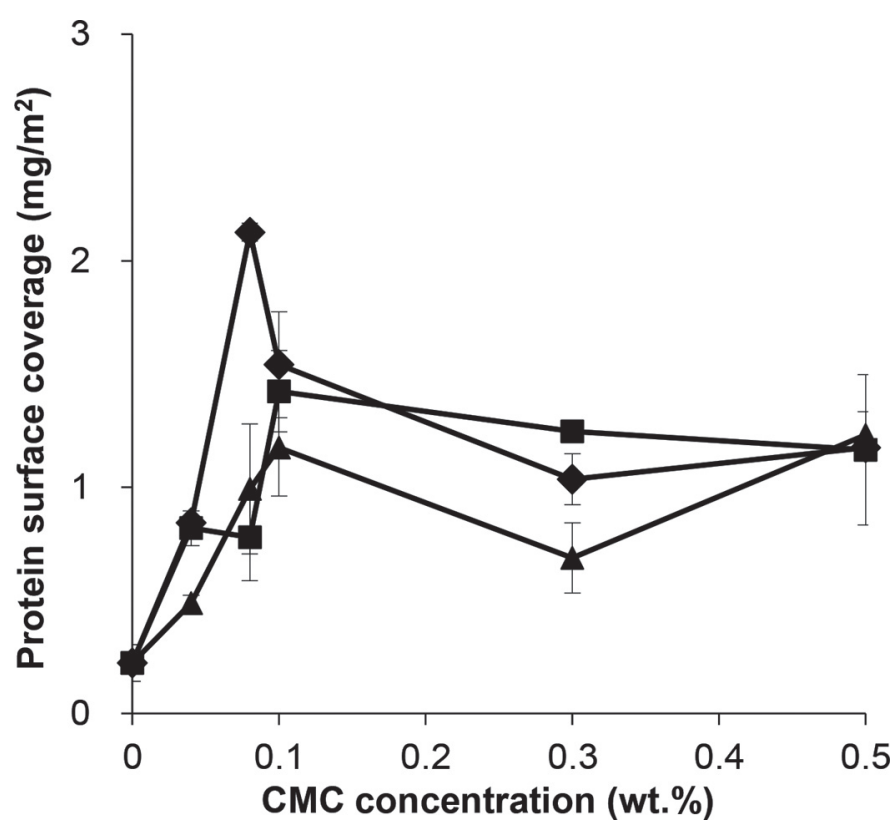

Figure 4. Protein surface coverage of emulsion droplets as a function of carboxymethylcellulose (CMC) concentration; ( $\mathbf{\Delta}$ ) CMC 270 $\mathrm{kDa}$, (Ш) CMC $750 \mathrm{kDa}$, ( ) CMC 2,500 kDa. Error bars represent $\mathrm{SD}$. stabilized by WPI alone. Protein surface coverage continued to increase as $\mathrm{CMC}$ concentration increased up to 0.08 or $0.1 \%$. Further increase in CMC concentration did not cause a significant change in protein surface coverage, which could be attributed to the saturation of WPI/CMC complex at the surface of the oil droplets. These results coincided with increased $\zeta$-potential and decreased droplet size with increasing CMC concentration up to $0.1 \%$ before reaching a plateau at higher concentrations (Figures 1 and 2).

No clear effect of the $\mathrm{M}_{\mathrm{w}}$ of CMC on protein surface coverage was noted; however, interestingly, maximum protein surface coverage of $2.13 \mathrm{mg} / \mathrm{m}^{2}$ was observed with emulsion containing $0.08 \%$ CMC 2,500k. This highest protein surface coverage coincided with the smallest droplet size at this condition, as previously shown, which could be due to an improvement in interfacial activity. The formation of a thick and compact interfacial layer around oil droplet surface and the saturated concentration of protein could provide strong steric stabilization against aggregation or flocculation and coalescence (Dickinson et al., 1997a; Li et al., 2012b).

\section{Emulsion Stability}

Figure 5 shows the effect of the $\mathrm{M}_{\mathrm{w}}$ and concentration of CMC on creaming stability of WPI-stabilized emulsions during $15 \mathrm{~d}$ of storage. Without CMC, it was not possible to prepare a stable emulsion at $\mathrm{pH}$ 5.2. The highly flocculated emulsion separated into an opaque cream layer at the top and a transparent serum layer at the bottom within $3 \mathrm{~h}$ of preparation (data not shown), suggesting that all of the droplets were aggregated and rapidly moved upwards due to higher gravitational stress. Addition of CMC led to more stable emulsions with a clear influence from the effects of $\mathrm{M}_{\mathrm{w}}$ and concentration. Overall, improved creaming stability coincided with smaller droplet size, increased negatively charge of the droplets, or higher viscosity of the serum phase at high CMC concentrations (Hermar et al., 2001; Singh et al., 2003; Harnsilawat et al., 2006; Li et al., 2012a; Long et al., 2013).

Overall, emulsions prepared with higher- $\mathrm{M}_{\mathrm{w}} \mathrm{CMC}$ were more stable compared with those with lower- $\mathrm{M}_{\mathrm{w}}$ CMC especially after $15 \mathrm{~d}$ of storage (Figure 6). These results were in accordance with a previous study that showed acidified milk drinks to be more stable when stabilized by CMC with higher $\mathrm{M}_{\mathrm{w}}$ compared with CMC with lower $\mathrm{M}_{\mathrm{w}}$ (Du et al., 2009). It was described that higher viscosity induced by the nonadsorbed high$\mathrm{M}_{\mathrm{w}}$ CMC could contribute to the higher stability of the system. It should be noted that, though a similar mechanism may apply, the stability of acidified milk drinks 

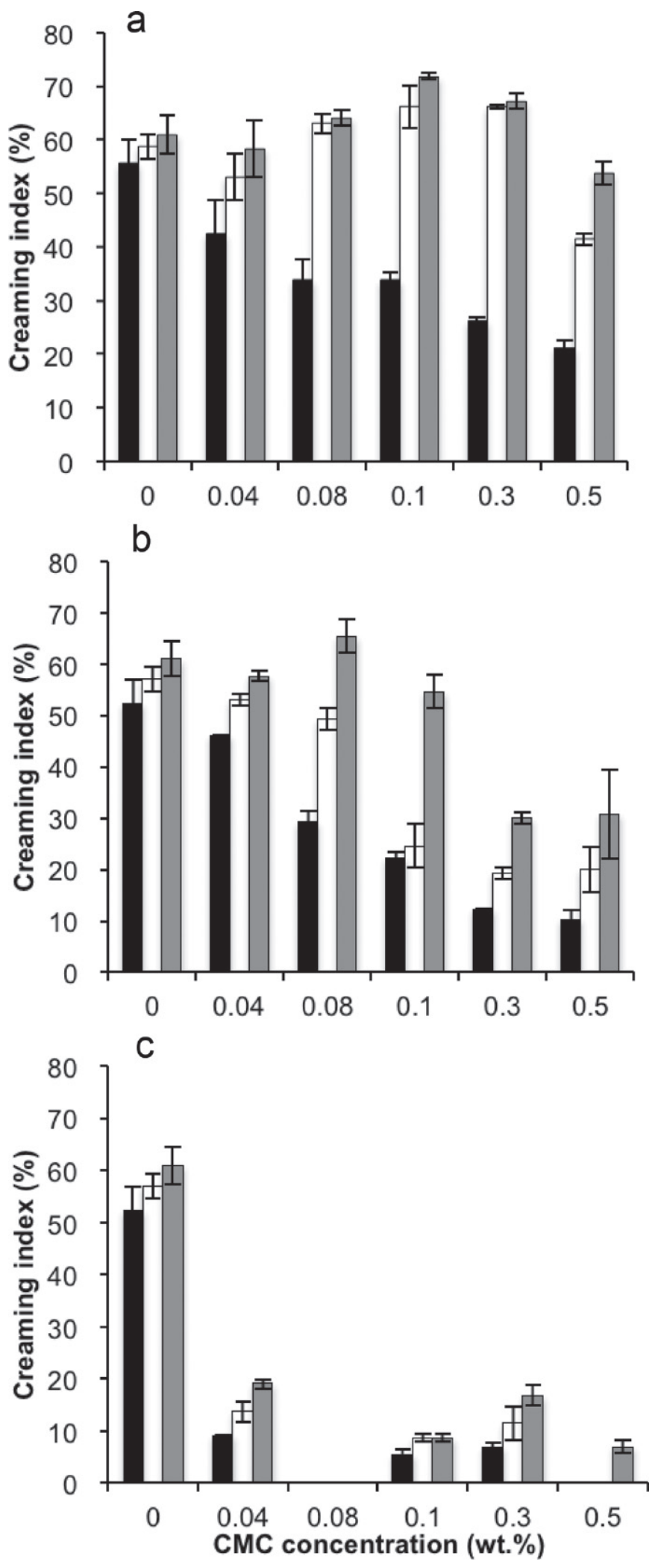

Figure 5. Creaming stability of emulsions prepared with different molecular weight of carboxymethylcellulose (CMC) stored quiescently for $15 \mathrm{~d}$ at room temperature: (a) CMC $270 \mathrm{kDa}$, (b) CMC $750 \mathrm{kDa}$, (c) CMC 2,500 kDa; (black bar) d 5, (white bar) d 10, (gray bar) d 15. in Du et al. (2009) was the stability of the proteins and not the oil droplets. In soy globulin and dextran mixed system, Semenova (1996) suggested that increasing $\mathrm{M}_{\mathrm{w}}$ of dextran favored coacervation with soy globulin because larger size polysaccharide was more accessible for the protein. In addition, Li et al. (2012b) pointed out that polysaccharides with large size adsorbed onto interfaces and protruded into the continuous phase acting as a thick steric layer, which provided effective stabilization between emulsion droplets and acted in concert with electrostatic repulsive forces. Better stability observed with emulsions containing CMC 2,500k over the lower- $\mathrm{M}_{\mathrm{w}} \mathrm{CMC}$ across all $\mathrm{CMC}$ concentrations could be due to the formation of thick steric stabilizing layer.

The effect of CMC concentration can be clearly observed and was dependent on the $\mathrm{M}_{\mathrm{w}}$ of CMC. For CMC 270k, increasing CMC concentration led to more stable emulsions within $5 \mathrm{~d}$ of storage. However, extensive creaming was observed on d 10, with creaming index $>40 \%$ even at $0.5 \%$ CMC (Figure 5a). For CMC $750 \mathrm{k}$, higher $\mathrm{CMC}$ concentration led to lower degree of creaming across all storage time, but extensive creaming (e.g., CI >30\%) was observed on d 15 (Figure 5b). Improved short-term stability at high CMC concentration of CMC $270 \mathrm{k}$ and $750 \mathrm{k}$ could result from increased emulsion viscosity. Addition of only $0.04 \%$ of CMC $2,500 \mathrm{k}$ reduced the creaming index from 55.6 (control) to $9.2 \%$ and from 58.5 to $19.7 \%$ after 5 and 15 d of storage, respectively. Improved creaming stability of CMC 2,500k could be due to a nonflocculated emulsion system, as shown by more Newtonian behavior. Interestingly, emulsion with $0.08 \% \mathrm{CMC} 2,500 \mathrm{k}$ was the most stable and no separation was noted after $15 \mathrm{~d}$ of storage (Figure $5 \mathrm{c}$ and $6 \mathrm{c}$ ). It should be noted that, at $0.08 \%$ CMC, all emulsions showed shear-thinning behavior with similar viscosity values; however, they showed significant differences in creaming stability. This suggested that the droplets were more likely to be coalesced in emulsions with CMC 270k and 750k, as coalescence leads to an increased creaming rate but has little effect on emulsion viscosity (McClements, 2005). The main reason for maximum stability of emulsion containing $0.08 \%$ CMC 2,500k was likely due to the highest protein surface coverage. Larger surface absorption can lead to increased thickness of the interfacial layer; hence, both strong electrostatic repulsion and steric repulsion between the WPI/CMC-coated droplets prevent aggregation (Harnsilawat et al., 2006). This particular sample also had smallest droplet size and highest negative charge (Figures 1 and 2). Further increases in CMC 2,500k concentration to 0.1 and $0.3 \%$ led to less stable systems, possibly from depletion flocculation caused by the nonadsorbed CMC molecules 

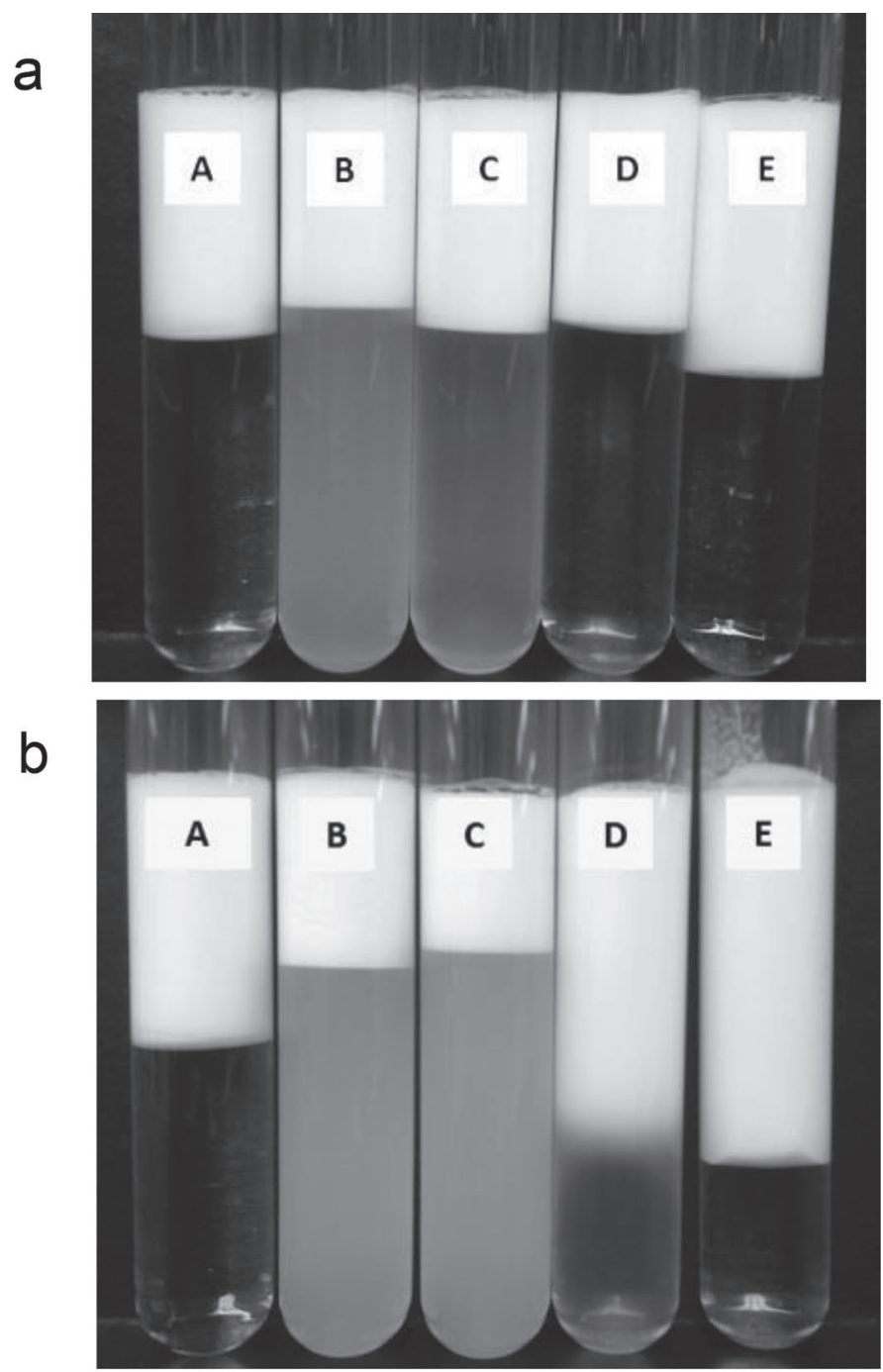

C

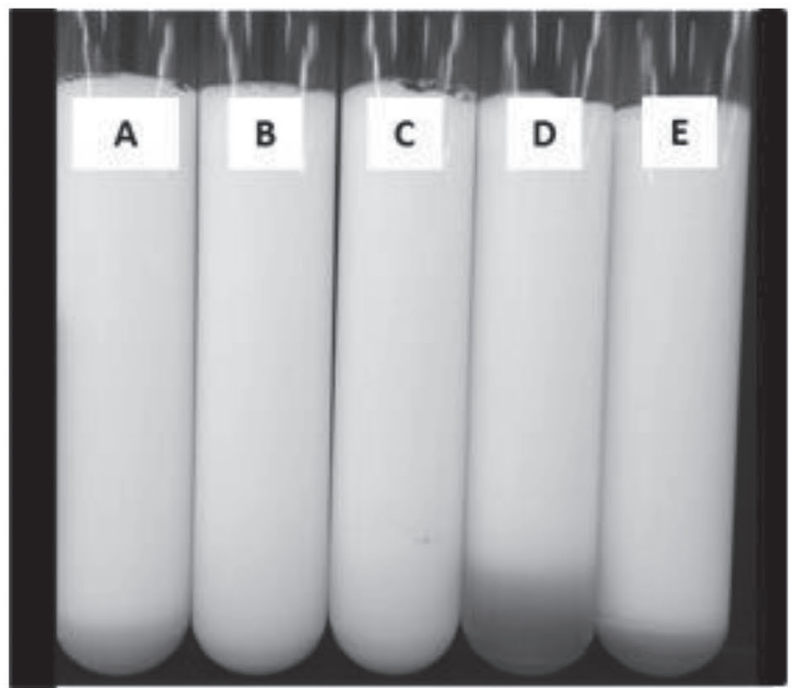

Figure 6. Whey protein isolate/carboxymethylcellulose (CMC)stabilized emulsions stabilized containing CMC $270 \mathrm{kDa}$ (a), $750 \mathrm{kDa}$ (b), and 2,500 kDa (c) at different CMC concentrations after $15 \mathrm{~d}$ storage. A to E: $0.04,0.08,0.1,0.3$, and $0.5 \%$, respectively.
(Dickinson et al., 1997b; Liu et al., 2012). Emulsion with $0.5 \%$ CMC $2,500 \mathrm{k}$ were more stable than at 0.1 and $0.3 \%$. This was likely due to the high serum viscosity of this sample, resulting in less depletion flocculation; thus, the rate and extent of phase separation may be impeded (Dickinson, 2003; Long et al., 2013). However, it did not contribute to the long-term stability of the emulsion system because the emulsion gradually separated after $10 \mathrm{~d}$ of storage. Similar behavior has been reported on emulsion systems with the addition of a large amount of polysaccharide (Ye et al., 2004; Sun et al., 2007; Long et al., 2013). In our study, it is clearly shown that the minimum or optimum CMC concentration needed for stable emulsion depends on the size or $\mathrm{M}_{\mathrm{w}}$ of CMC. The CMC concentration needed for stabilizing emulsion was lower with higher- $\mathrm{M}_{\mathrm{w}}$ CMC. As previously stated, it could be that high- $\mathrm{M}_{\mathrm{w}} \mathrm{CMC}$ with longer chains would form a thicker adsorbed layer, leading to a more stable system through steric stabilization.

\section{CONCLUSIONS}

The presence of CMC led to the formation of WPICMC complex and resulted in improved surface properties of protein, as shown by higher protein surface coverage and significantly more negative charges on the droplets. The WPI-CMC stabilized emulsions showed smaller droplet size and had improved stability. Above $0.1 \%$ CMC, the droplet surfaces were saturated with WPI-CMC complex and uncomplexed WPI, as shown by little or no change in droplet size, $\zeta$-potential, and protein surface coverage. Further addition of CMC increased the viscosity of the continuous aqueous phase, resulting in increased stability against creaming. Emulsions containing higher- $\mathrm{M}_{\mathrm{w}} \mathrm{CMC}$ were more stable compared with those with low- $\mathrm{M}_{\mathrm{w}} \mathrm{CMC}$, with the maximum stability achieved at $0.08 \%$ CMC 2,500k. The high- $\mathrm{M}_{\mathrm{w}} \mathrm{CMC}$ likely provided improved surface charge and formed stronger complex with WPI, resulting in enhanced electrostatic as well as steric repulsion of the adsorbed layers and contributing to the stability of acidified WPI/CMC-stabilized emulsions.

\section{ACKNOWLEDGMENTS}

The authors thank Davisco Foods International Inc. (Le Sueur, MN) and CP Kelco Inc. (Atlanta, GA) for providing whey protein isolate and $\mathrm{CMC}$, respectively. This material is based upon work that is supported by the National Institute of Food and Agriculture, USDA (Washington, DC), Hatch project under 233858. 


\section{REFERENCES}

Chern, C. 2008. Colloidal stability. Page 11-14 in Principles and Applications of Emulsion Polymerization. C. Chern, ed. Wiley, Hoboken, NJ.

Dickinson, E. 1998. Stability and rheological implications of electrostatic milk protein-polysaccharide interactions. Trends Food Sci. Technol. 9:347-354.

Dickinson, E. 2003. Hydrocolloids at interfaces and the influence on the properties of dispersed system. Food Hydrocoll. 17:25-39.

Dickinson, E. 2008. Interfacial structure and stability of food emulsions as affected by protein-polysaccharide interactions. Soft Matter 4:932-942.

Dickinson, E., M. Golding, and M. J. W. Povey. 1997a. Creaming and flocculation of oil-in-water emulsions containing sodium caseinate. J. Colloid Interface Sci. 185:515-529.

Dickinson, E., M. Golding, and M. J. W. Povey. 1997b. Creaming and flocculation of oil-in-water emulsions containing sodium caseinate. J. Colloid Interface Sci. 185:515-529.

Dickinson, E., and K. Pawlowsky. 1997. Effect of ı-carrageenan on flocculation, creaming, and rheology of a protein-stabilized emulsion. J. Agric. Food Chem. 45:3799-3806.

Doublier, J.-L., C. Garnier, D. Renard, and C. Sanchez. 2000. Protein-polysaccharide interactions. Curr. Opin. Colloid Interface Sci. $5: 202-214$

Du, B., J. Li, H. Zhang, L. Huang, P. Chen, and J. Zhou. 2009. Influence of molecular weight and degree of substitution of carboxymethylcellulose on the stability of acidified milk drinks. Food Hydrocoll. 23:1420-1426.

Franco, J. M., M. Berjano, and A. M. Guerrero. 1995. Flow behavior and stability of light mayonnaise containing a mixture of egg yolk and sucrose stearate as emulsifiers. Food Hydrocoll. 9:111-121.

Ganzevles, R. A., K. Zinoviadou, T. van Vliet, M. A. Cohen Stuart, and H. H. de Jongh. 2006. Modulating surface rheology by electrostatic protein/polysaccharide interactions. Langmuir 22:1008910096.

Girard, M., S. L. Turgeon, and S. F. Gauthier. 2002a. Interbiopolymer complexing between beta-lactoglobulin and low- and high- methylated pectin measured by potentiometric titration and ultrafiltration. Food Hydrocoll. 16:585-591.

Girard, M., S. L. Turgeon, and P. Paquin. 2002b. Emulsifying properties of whey protein-carboxymethylcellulose complex. J. Food Sci. 67:113-119.

Girard, M., S. L. Turgeon, and P. Paquin. 2002c. Influence of hydrocolloids on phase separation and emulsion properties of whey protein isolate. Food Eng. Phys. Prop. 67:113-119.

Goff, H. 2014. Milk proteins: Functional ingredients in food. Page 11-18 in Gums and Stabilisers for the Food Industry 17: The Changing Face of Food Manufacture: The Role of Hydrocolloids. P. Williams and G. Phillps, ed. The Royal Society of Chemistry, Cambridge, UK

Guzey, D., and D. McClements. 2007. Impact of electrostatic interactions on formation and stability of emulsions containing oil droplets coated by $\beta$-lactoglobulin-pectin complexes. J. Agric. Food Chem. 55:475-485.

Harnsilawat, T., R. Pongsawatmant, and D. McClements. 2006. Stabilization of model beverage cloud emulsions using protein-polysaccharide electrostatic complexes formed at the oil-water interface. J. Agric. Food Chem. 54:5540-5547.

Hermar, Y., M. Tamehana, P. A. Munro, and H. Singh. 2001. Influence of xanthan gum on the formation and stability of sodium caseinate oil-in-water emulsions. Food Hydrocoll. 15:513-519.

Jourdain, L. S., C. Schmitt, M. E. Leser, B. S. Murray, and E. Dickinson. 2009. Mixed layers of sodium caseinate + dextran sulfate: influence of order of addition to oil-water interface. Langmuir 25:10026-10037.

Jourdain, L. S., M. E. Leser, C. Schmitt, M. Michel, and E. Dickinson. 2008. Stability of emulsions containing sodium caseinate and dextran sulfate: Relationship to complexation in solution. Food Hydrocoll. 22:647-659.
Khalloufi, S., M. Corredig, H. D. Goff, and M. Alexander. 2009. Flaxseed gums and their adsorption on whey protein-stabilized oil-inwater emulsions. Food Hydrocoll. 23:611-618.

Klein, M., A. Aserin, I. Svitov, and N. Garti. 2010. Enhanced stabilization of cloudy emulsions with gum Arabic and whey protein isolate. Colloids Surf. B Biointerfaces 77:75-81.

Koupantsis, T., and V. Kiosseoglou. 2009. Whey protein-carboxymethylcellulose interaction in solution and in oil-in-water emulsion systems. Effect on emulsion stability. Food Hydrocoll. 23:1156-1163.

Laneuville, S. I., P. Paquin, and S. L. Turgeon. 2000. Effect of preparation conditions on the characteristics of whey protein-xanthan gum complexes. Food Hydrocoll. 14:305-314.

Laplante, S., S. Turgeon, and P. Paquin. 2005a. Effect of pH, ionic strength, and composition on emulsion stabilising properties of chitosan in a model system containing whey protein isolate. Food Hydrocoll. 19:721-729.

Laplante, S., S. Turgeon, and P. Paquin. 2005b. Emulsion stabilizing properties of various chitosans in the presence of whey protein isolate. Carbohydr. Polym. 59:425-434.

Li, X., Y. Fang, S. Al-Assaf, G. O. Phillips, and F. Jiang. 2012b. Complexation of bovine serum albumin and sugar beet pectin: stabilising oil-in-water emulsions. J. Colloid Interface Sci. 388:103-111.

Li, J.-L., Y.-Q. Cheng, P. Wang, W.-T. Zhao, L.-J. Yin, and M. Saito. 2012a. A novel improvement in whey protein isolate emulsion stability: Generation of an enzymatically cross-linked beet pectin layer using horseradish peroxidase. Food Hydrocoll. 26:448-455.

Liu, L., Q. Zhao, T. Liu, J. Kong, Z. Long, and M. Zhao. 2012. Sodium caseinate/carboxymethylcellulose interactions at oil-water interface: Relationship to emulsion stability. Food Chem. 132:18221829

Long, Z., Q. Zhao, T. Liu, W. Kuang, J. Xu, and M. Zhao. 2013. Influence of xanthan gum on physical characteristics of sodium caseinate solutions and emulsions. Food Hydrocoll. 32:123-129.

Lorenzo, G., N. Zaritzky, and A. Califano. 2008. Modeling rheological properties of low-in-fat o/w emulsions stabilized with xanthan/ guar mixtures. Food Res. Int. 41:487-494.

Lutz, R., A. Aserin, L. Wicker, and N. Garti. 2009. Double emulsions stabilized by a charged complex of modified pectin and whey protein isolate. Colloids Surf. B Biointerfaces 72:121-127.

McClements, D. J. 2005. Food Emulsions: Principles, Practice and Techniques. CRC Press, Boca Raton, FL.

Nakamura, A., R. Yoshida, H. Maeda, and M. Corredig. 2006. Soy soluble polysaccharide stabilization at oil-water interfaces. Food Hydrocoll. 20:277-283.

Neirynck, N., P. Van der Meeren, M. Lukaszewicz-Lausecker, J. Cocquyt, D. Verbeken, and K. Dewettinck. 2007. Influence of pH and biopolymer ratio on whey protein-pectin interactions in aqueous solutions and in $\mathrm{O} / \mathrm{W}$ emulsions. Colloids Surf. A Physicochem. Eng. Asp. 298:99-107.

Nussinovitch, A. 1997. Hydrocolloid Applications: Gum Technology in the Food and Other Industries. Blackie Academic and Professional, London, UK.

Pereyra, R., K. Schmidt, and L. Wicker. 1997. Interaction and stabilization of acidified casein dispersions with low and high methoxyl pectin. J. Agric. Food Chem. 45:3448-3451.

Pinotti, A., A. Bevilacqua, and N. Zaritzky. 1997. Optimization of the flocculation stage in a model system of a food emulsion waste using chitosan as polyelectrolyte. J. Food Eng. 32:69-81.

Quemada, D., and C. Berli. 2002. Energy of interaction in colloids and its implications in rheological modeling. Adv. Colloid Interface Sci. 98:51-85.

Schmitt, C., and S. L. Turgeon. 2011. Protein/polysaccharide complexes and coacervates in food systems. Adv. Colloid Interface Sci 167:63-70.

Semenova, M. G. 1996. Factors determining the character of biopolymer-biopolymer interactions in multicomponent aqueous solutions modeling food systems. Page 37-49 in Macromolecular Interactions in Food Technology. N. Parris, A. Kato, L. K. Creamer, and J. P. Parris, ed. American Chemical Society, Washington, DC. 
Singh, H., M. Tamehana, Y. Hemar, and P. A. Munro. 2003. Interfacial compositions, microstructure and stability of oil-in-water emulsions formed with mixtures of milk proteins and $\kappa$-carrageenan: 2 . Whey protein isolate (WPI). Food Hydrocoll. 17:549-561.

Sun, C., S. Gunasekaran, and M. P. Richards. 2007. Effect of xanthan gum on physicochemical properties of whey protein isolate stabilized oil-in-water emulsions. Food Hydrocoll. 21:555-564.

Surh, J., E. Decker, and D. McClements. 2006. Influence of $\mathrm{pH}$ and pectin type on properties and stability of sodium-caseinate stabilized oil-in-water emulsions. Food Hydrocoll. 20:607-618.

Turgeon, S. L., M. Beaulieu, C. Schmitt, and C. Sanchez. 2003. Protein-polysaccharide interactions: phase-ordering kinetics, thermo- dynamic and structural aspects. Curr. Opin. Colloid Interface Sci. 8:401-414.

Vardhanabhuti, B., U. Yucel, J. N. Coupland, and E. A. Foegeding. 2009. Interactions between $\beta$-lactoglobulin and dextran sulfate at near neutral $\mathrm{pH}$ and their effect on thermal stability. Food Hydrocoll. 23:1511-1520.

Ye, A., Y. Hemar, and H. Singh. 2004. Influence of polysaccharides on the rate of coalescence in oil-in-water emulsions formed with highly hydrolyzed whey proteins. J. Agric. Food Chem. 52:5491-5498.

Ye, A., M. Srinivasan, and H. Singh. 2000. Influence of $\mathrm{NaCl}$ addition on the properties of emulsions formed with commercial calcium caseinate. Food Chem. 69:237-244 